\title{
The Effect of Different Additives on Semen Freezing of Aksaray Malakl1 Shepherd Dog
}

\author{
Caner ÖZTÜRK, Şükrü GÜNGÖR², Halit Furkan DEMİR \\ ${ }^{1}$ Aksaray University, Faculty of Veterinary Medicine, Reproduction and Artificial Insemination Department, 68100, Aksaray, Turkey \\ ${ }^{2}$ Burdur Mehmet Akif Ersoy University, Faculty of Veterinary Medicine, Reproduction and Artificial Insemination Department, 15030, \\ Burdur, Turkey \\ ${ }^{3}$ Aksaray University, Faculty of Veterinary Medicine, 68100, Aksaray, Turkey
}

\begin{abstract}
The aim of this study was to investigate the spermatological parameters of Aksaray Malakli shepherd dog after freezethawing semen with various additives. Study groups were set up as Tris-based extender (TBE) +trehalose (10mM), $\mathrm{TBE}+$ methionine $(2 \mathrm{mM})$ andcontrol. Sperm was collected by bulbus glandis massage (Digital Manipulation). Diluted semen samples were aspirated into $0,25 \mathrm{ml}$ French straws and equilibrated at $5{ }^{\circ} \mathrm{C}$ for $1,5 \mathrm{~h}$. After equilibration, the straws were frozen in liquid nitrogen vapor, plunged into liquid nitrogen for storage. For determination the sperm volume, grade semen collecting tubes were used and the results were recorded in milliliters. The sperm concentration was determined with hemocytometric method as $\mathrm{mm}^{3}$. Eosin-nigrosine staining method was used for live sperm percentages. The HOS-test was performed to determine the ratio of intact spermatozoa membrane. When the freeze-thawing results are statistically examined with one-way analysis of variance, methionine group, motility $(52,5 \% \pm 2,7)$ and HOS test analysis $(43,1 \% \pm 2,9)$, $(41,5 \% \pm 3,1 ; 33,2 \% \pm 2,9)$ shown significant differences compared control $(41,5 \% \pm 3,1 ; 33,2 \% \pm 2,9)$ group $(p<0,05)$. The best result in the live sperm percentages was observed in methionine group but there was no statistically significant difference between the groups ( $\mathrm{p}>0.05$ ).In the trehalose group, motility, HOS test and live sperm percentages results were $50.0 \%$ $\pm 3,9 ; 60,6 \% \pm 3,7 ; 38,4 \pm 3,6 \%$, respectively. As a result of the study, it was determined that methionine $2 \mathrm{mM}$ added to trisbased diluent in Aksaray Malaklı shepherd dog sperm was beneficial on spermatological parameters. The cryoprotective effect of methionine was found to be stronger than trehalose and control group.
\end{abstract}

Keywords: Malakli, methionine, sperm, trehalose

\section{$* * *$ \\ Farklı Katkı Maddelerinin Aksaray Malaklı Çoban Köpeği Spermasının Dondurulmasına Etkisi}

\section{ÖZ}

Bu çalışmanın amacı, Aksaray Malaklı çoban köpeği spermasının farklı katkı maddeleri içeren sulandırıcılar ile dondurulup çözüm sonu spermatolojik parametrelerin araştırılmasıdır. Çalışma grupları, Tris ana stok (TAS)+trehaloz (10 mM), TAS+metiyonin $(2 \mathrm{mM})$ ve kontrol olarak oluşturuldu. Köpeklerden sperma digital maniplasyon yöntemi ile alındı. Sulandırma işlemi tamamlanan sperma örnekleri $0.25 \mathrm{ml}$ lik payetlere çekildi. Payetlenen spermalar 1.5 saat $+5^{\circ} \mathrm{C}^{\prime}$ ta ekilibrasyona tabi tutuldu. Ekilibrasyon sonrası payetler sıvı azot buharında donduruldu ve sıvı azot içerisinde saklandı. Sperma hacminin belirlenmesinde dereceli sperma toplama tüpleri kullanıldı ve sonuçları mililitre olarak kaydedildi. Hemositometrik yöntem ile spermatozoon konsantrasyonu belirlenerek $\mathrm{mm}^{3}$ olarak kaydedildi. Ölü canlı spermatozoa muayenesi için eosin-nigrosin boyama yöntemi kullanıldı. Spermatozoa plazma membran bütünlügü oranını belirlemek için Hipo osmotik şişirme (HOS) testi yapıldı. Sonuçlar istatistiksel açıdan tek yönlü varyans analizi ile incelendiğinde çözüm sonu metiyonin grubunda motilite $(\% 52,5 \pm 2,7)$ ve HOS test parametreleri açisindan $(\% 43,1 \pm 2,9)$, kontrol grubuna $(\% 41,5 \pm 3,1 ; \% 33,2 \pm 2,9)$ göre istatistiksel farklılık gözlendi $(\mathrm{p}<0,05)$. Çözüm sonu canlı spermatozoa oranına en yüksek metiyonin grubunda ulaşılmasına rağmen gruplar arası istatistiksel farklılık bulunamadı ( $\mathrm{p}>0,05)$. Trehaloz grubunda ise motilite, HOS test ve canlı spermatozoa oranı sırasıly $\% 50,0 \pm 3,9 ; \% 60,6 \pm 3,7 ; \% 38,4 \pm 3,6$ olarak bulundu. Çalışmanın sonucunda Aksaray Malaklı çoban köpeği spermasında tris bazlı sulandırıcıya eklenen metiyonin 2mM dozunun spermatolojik parametreler üzerine faydalı olduğu belirlenmiştir. Metiyoninin kriyoprotektif etkinliğinin trehaloz ve kontrol grubuna göre daha güçlü olduğu kanısına varıldı.

Anahtar Kelimeler: Malakl, metiyonin, sperma, trehaloz

To cite this article: Öztürk C. Güngör Ş. Demir H.F. The Effect of Different Additives on Semen Freezing of Aksaray Malakh Shepherd Dog. Kocatepe Vet J. (2019) 12(3):329-335 


\section{GİRİŞ}

Ülkemizde çoban köpekleri Akbaş ve Karabaş olmak üzere iki grup altında toplanmaktadır. Kangal 1 rk1 köpekler grubunun en ünlü üyesi olmakla beraber Malaklı, Karabaş ve Karakaya 1rk1 köpeklerde mevcuttur. Malaklı özellikle Aksaray, Şereflikoçhisar ve Nevşehir olmak üzere Türkiye'nin değişik bölgelerinde bulunmaktadır. Malaklı Karabaş köpekleri Kangal ırkına kıyasla daha iri yapılı, kısa kılll, kuyruk yapısının Kangal köpeğinde olduğu kadar kıvrık olmadığı, insana ve diğer köpeklere karşı daha saldırgan olduğu yapılan çalışmalar ile belirlenmiştir (Atasoy ve ark. 2014). Saf köpek yetiştiriciliğine olan ilginin artmasıyla birlikte yardımcı üreme teknikleri küçük hayvanlarda uygulaması talep edilen yöntemlerden olmuştur (Peña ve ark. 2006). Diğer hayvanlarda olduğu gibi köpek yetiştiriciliğinde de genetik yapının ve gen kaynaklarının korunması büyük önem taşımaktadır. Bunun sağlanabilmesi için 1 rkın spermatolojik özelliklerinin belirlenmesi ve spermanın katk1 maddeleri ile dondurulması çalışmaları uzun ylllardır yapilmaktadır (Tosun ve Uysal 2007).

Dondurulmuş sperma ile suni tohumlama diğer hayvan türlerinde olduğu gibi köpek spermasında da uygulanmaktadır. İlk başarılı dondurma denemesi 1954 yılında Rowson tarafindan gerçekleştirilmiştir (England 1992). Köpek spermasinin dondurulmasina karş1 günümüzde artan bir ilgi gözlenmektedir (Peña ve ark. 2006). Dondurulmuş sperma ile yetiştirme programlarının birçok faydası bulunmaktadır. Bunların en önemlisi üstün irk özelliklerini taşıyan köpeklerin genetik materyalinin uzun süre saklanabilmesidir (Neagu ve ark.2010). Diğer evcil hayvanlarda olduğu gibi spermanın uzun süreli saklanabilmesi için sıvı nitrojen ile dondurulması en iyi yöntemdir. $\mathrm{Bu}$ yöntemle dondurulan spermanın çözüm sonu motilitesi \%60-70 arasında değişmekte ve fertilite oranı \%60 civarında olmaktadır (Álamo ve ark. 2005).

Serbest radikallerin hücrede artışı ve hücre fonksiyonlar1 üzerinde yaptıkları olumsuz etki (oksidatif hasar) 'oksidatif stres' olarak adlandirllir (Tekcan 2009). Sperma hücrelerinin membran yapis1 protein, glikoprotein ve glikolipit içeren iki sıralı fosfolipit katmandan oluşan akıcı mozaik tarzındadır. $\mathrm{Bu}$ yapının \%70 oranında doymamış fosfolipit içermesi, spermanın dondurulması sırasında dönüşümsüz sıvı fazdan jel fazına geçmesine neden olmaktadır. Bu değișim canlılığ azaltmakta ve sonucunda soğuk şoku ve oksidatif stres kökenli hasarlar gelişmektedir. Oksidatif stres, spermatozoa plazma membran kaybına, fonksiyonlarının zarar görmesi sonucunda motilite ve fertilite düşüşlerine neden olmaktadır (Watson 2000).

Spermatozoonlar normal şartlar altında az miktarda reaktif oksijen türleri (ROT) üretmektedir. ROT'un spermatozoonun kapasitasyonu, hiperaktivasyonu ve sperma-oosit füzyonu için gerekli olduğu belirtilmektedir. Spermatozoonun sitoplazması düşük miktarda enzim içerdiği için plazma membranı yüksek miktarda doymamış yağ asidi içermektedir (Agarwal ve ark. 2008). Spermatozoon membranlarında yüksek miktarda bulunan doymamış yağ asitleri akışkanlık sağlaması ve spermatozoonun zona pellusidaya bağlanması için gereklidir. Bunun yanı sıra ROT saldırısına karşı hücreyi savunmasız bırakmaktadır (Agarwal ve ark. 2014). ROT oluşumu ve membran lipit peroksidasyonu sperm canlılığ ve fertilitesi için önemli bir problemdir (Guthrie ve Welch 2012). Lipitlerin peroksidasyonu, serbest radikallerin hücre membranına saldırması sonucu gerçekleşir. Serbest radikaller, hücre membranının dengesini ortadan kaldırarak, hızlı hücre ve doku hasarına sebep olurlar. Lipit peroksidasyon spermanın motilitesini düşürücü etki göstermektedir (Agarwal ve ark. 2008, Tekcan 2009).

Spermatozoa seminal plazmada bulunan antioksidanlar ile kendisini oksidatif strese karşı korumaya çalışmaktadır (Kim ve Parthasarathy 1998). Serbest radikallerin zararlı etkilerinden korunmak için hücreler bunları nötralize eden antioksidanlar oluşturmaktadır. Serbest radikallerin olușum hızı ve bunların antioksidanlar tarafindan nötralize edilme hızı arasında bir denge olması gereklidir. Böylece hücre serbest radikallerin olumsuz etkilerinden korunmaktadır. Eğer bu denge serbest radikaller lehine bozulursa, üretimden daha yavaş nötralize edilirlerse, hücrede serbest radikallerin miktarı yükselir. Hücreler hafif oksidatif stresi tek başlarına giderebilseler de genellikle antioksidan enzim sistemlerini kullanırlar. Ancak, hücre içi savunma sistemlerinin yetersiz kaldığ durumlarda, oksidan hasara duyarlı DNA, protein, karbonhidrat ve lipitler gibi hücresel makromoleküller hasar görmektedir (Sabuncuoğlu ve Özgüneş 2011). Dondurulupçözdürülen sperm hücrelerinde antioksidan kapasitenin azalıp, reaktif oksijen radikal oluşumunun artması spermatolojik parametreler ve fertiliteyi olumsuz etkilemektedir. Çözdürülmüş sperma hücreleri, taze spermaya göre peroksidasyona karşı daha hassastır (Kulaksız ve Daşkın 2009). Tüm bu etmenlerden dolayı yapılan araştırmalar spermanın dondurulmasi sirasinda sulandiricilara antioksidan özelliği yüksek maddelerin ilave edilmesi üzerine yoğunlaşmıştır.

Metiyonin, esansiyel amino asitlerden bir tanesidir ve glutatyon için bir öncü amino asit görevi görür. Bu özellikleri sayesinde, ROT azalır ve kriyoprezervasyon sırasında hücreleri oksidatif strese karşı korur. İçeriğindeki tiyol gurubu sayesinde metiyonin kurşun ile şelat oluşturur ve hücrelerden uzaklaşmasını sağlar. Metiyonin ayrica poliaminler (spermin ve spermidin) sentezini sağlar (Reed 1990, Patra ve ark. 2001, Bouyeh 2012). Trehaloz hücre içindeki suyun dış 
ortama çıkışını sağlayarak dondurma sırasında meydana gelen buz kristali oluşumunu azaltır. Enerji kaynağ1 olarak ve ozmotik basıncı düzenleyerek kriyoprotektif etkinlik gösterir (Garcia ve Graham 1989, Abdelhakeam ve ark.1991). Şekerlerin dondurma-çözdürme sirasında meydana gelen soğuk şokunun önlenmesinde antioksidatif ve kriyoprotektan özelliklerinin olduğu birçok çalışmada bildirilmiştir (Woelders ve ark. 1997, Malo ve ark. 2010). Trehaloz ve taurin sulfonik amino asit grubundan olup enzimatik olmayan antioksidanlar olarak bilinmektedir (Reddy ve ark. 2010). Disakkaritler spermanın dondurulması sürecinde ozmotik değişimlere karşı membranın fosfolipit bağlarına etki ederek hücre hasarının önüne geçmeye çalıştığ1 bildirilmektedir (Molinia ve ark.1994, Liu ve ark. 1998, Gungor ve ark. 2018). Trehalozun koç, boğa ve fare spermasının dondurulmasında başarılı bir kriyoprotektan etki gösterdiği belirtilmektedir (Storey ve ark.1998, Bilodeau ve ark. 2001, El-Alamy ve Foote 2001) Köpek spermasının kısa süreli saklanmasında ve dondurulmasına ilişkin çeşitli antioksidanlar ile yapılmış birçok araştırma mevcuttur (Uysal ve ark.2005, Martins-Besa ve ark.2007, Michael ve ark.2009, Bencharif ve ark. 2012, İnanç ve ark. 2018).Bu çalışmada, Aksaray Malaklı Çoban köpeği spermasinda metiyonin ve trehaloz içeren sulandırıcıların çözüm sonu sperm motilite, ölü canlı ve plazma membran bütünlüğü üzerine etkisinin belirlenmesi amaçlanmıştır.

\section{MATERYAL ve METOT}

\section{Hayvanların seçimi}

Aksaray ilinde halk elinde yetiştiriciliği yapılan2-5 yaş aralığında 10 baş erkek Aksaray Malaklısı Çoban Köpeği (Türk Mastifi) kullanıldı. Sunulan çalışma için Mehmet Akif Ersoy Üniversitesi Hayvan Deneyleri Yerel Etik Kurulu'ndan gerekli izin (2016/217) alınd.

\section{Sperma sulandiricisının hazırlanmasi}

Çalışmada temel sperma sulandirıcı olarak Tris Ana Stok (TAS) solüsyonu (tris297.58 mM, sitrik asit 96.32 $\mathrm{mM}$, fruktoz $82.66 \mathrm{mM}$ ) kullanıldı (Güngör ve Bucak 2016). Bunun üzerine (sperma alınacağ1 gün) \%15 oranında taze yumurta sarısı eklendi ve 15 dakika 6000 devirde santrifüj işlemi uygulanarak supernatant kısmı uzaklaştırıldıktan sonra \%6 oranında gliserol eklenerek hazır hale getirildi. Daha önceki çalışmalar ışı̆̆ında, metiyonin ve trehaloz grupları belirlendi (Akalınve ark.2015) ve TAS (Kontrol), TAS + trehaloz $(10 \mathrm{mM})$, TAS + metiyonin $(2 \mathrm{mM})$ şeklinde çalışma grupları oluşturuldu

\section{Spermanin toplanmasi}

Köpeklerden sperma, bulbus glandise masaj yapılarak digital maniplasyon yöntemi ile alındı. Bulbus glandis şişmeye başladığında prepusyum geri çekilerek penis prepusyumdan çıkartıldı masaja devam edilirken penis arka bacaklar arasından geriye çevrildi ve sperma alınd1. Uygulamada her köpekten haftada iki kez olmak üzere toplam 6ejakülatın spermadan zengin 2 . Fraksiyonu kullanıldı. \%80 ve üzeri motilite ile mililitrede en az $400 \times 10^{6}$ sperma konsantrasyonuna sahip ejakülatlar bireysel olarak donduruldu.

\section{Spermada hacim, motilite ve yoğunluk muayenesi}

Spermanın hacminin belirlenmesi için dereceli sperma toplama kadehlerinden faydalandı ve elde edilen sonuç mililitre birimi ile belirlendi. Motilitenin tespitinde Sicaklığ $37^{\circ} \mathrm{C}$ ye ayarlanmış faz-kontrast mikroskopun 400x büyütmesinde lam-lamel arasina alınan bir damla sperma numunesi en az 5 mikroskop sahası incelenerek, başı yönünde ileriye doğru düzgün doğrusal hareket eden spermatozoonların tümüne oranı belirlendi. Motilite değerlerinin ortalaması \% motilite oranı olarak kaydedildi. Sperma yoğunluk muayenesi ise hemositometrik yöntem ile ml'de bulunan spermatazoon konsantrasyonu olarak belirlendi (Tekin 1994).

\section{Ölü-Canlı Muayenesi}

Spermatazoa canlılık oranı tespitinde Eosin-Nigrosin boyama yöntemi kullanıld. Bu yöntemde bir damla sperma ile bir damla Eosin boyası ve karışımın üzerinede bir damla Nigrosin boyası eklendi ve sürme froti hazırlanarak, mikroskobun 400x büyütmesinde 300 hücre sayılarak spermatazoonun baș kısmı boya almayanlar canlı olarak kaydedildi ve sonuç \% canlı oranı olarak belirlendi (Watson 1975).

\section{Hipo Osmotik Şişirme (HOS) Testi}

Sperma,100 mOsm hazırlanmış HOS solüsyonu (0,9 gram fruktoz 0,49 gram trisodyum sitrat, 100 ml'ye tamamlanarak)içerisinde tespit edilen numunelerden preperat 30 dakika $37^{\circ} \mathrm{C}$ 'ta inkübasyonu sonrasi fazkontrast mikroskobun 400x büyütmesinde 300 hücre sayılarak spermatozoa mebranlarının düşük ozmotik basınçta bütünlüğü incelendi. Kuyruğu kıvrık olan spermatozoonlar membran bütünlüğü sağlam olarak belirlendi (Tekin 1994, Kulaks1z 2009).

\section{İstatistiksel analizler}

Çalışmadan elde edilen veriler önemlilik testlerinden önce, tüm değişkenler parametrik test varsayımlarından normallik yönünden Shapiro Wilks ve Kurtosis test ile, varyansların homojenliği yönünden ise Levene's testi ile incelendi. Normal dağılım gösteren değişkenler arası farklılığın istatistiksel açıdan değerlendirilmesi tek yönlü varyans analizi (One Way Anova) ile yapild1. Gruplar aras1 farklılığın belirlenmesinde ileri aşama (post-hoc) testi olarak Duncan testi kullanıldı ve sonuçlar ortalama \pm standart sapma olarak verildi. IBM SPSS 21.0 paket programindan yararlanild. 


\section{BULGULAR}

Araştırma kapsamında hayvanlardan alınan ortalama sperma hacimleri ve ml deki spermatazoon sayis1 Tablo 1'de belirtilmiştir.

Metiyonin grubunda çözüm sonu motilite ve HOS test analizlerinde kontrol grubu ile istatistiksel farklılık tespit edilmiştir $(p<0,05)$. Canlllık muayenesinde en iyi sonuca yine metiyonin grubunda ulaşılmasına rağmen gruplar arası istatistiksel farklilik bulunamamıştır $\quad(p>0,05)$. Plazma membran bütünlüğü analizinde (HOS test) Trehaloz $10 \mathrm{mM}$ kontrol grubuna karşı sayısal üstünlük elde edilirken bu farklilik istatistiksel olarak önemli bulunmamıştır $(\mathrm{p}>0,05)$.

Tablo 1. Aksaray Malaklı köpeklerinde ortalama sperma miktarı ve yoğunluğu

Table 1. Mean of sperm volume and concentration of dogs which were used in the study

\begin{tabular}{ccc}
\hline Hayvan No & $\begin{array}{c}\text { Sperma Miktarı } \\
(\mathbf{m l})\end{array}$ & $\begin{array}{c}\text { Sperma Yoğunluğu } \\
\left(\mathbf{m m}^{3} / \mathbf{m l}\right)\end{array}$ \\
\hline 1. Hayvan & $1,5 \pm 0,22$ & $440 \pm 21,6 \times 10^{6}$ \\
2. Hayvan & $1,65 \pm 0,24$ & $615 \pm 28,57 \times 10^{6}$ \\
3. Hayvan & $2,15 \pm 0,12$ & $610 \pm 49,67 \times 10^{6}$ \\
4. Hayvan & $2,2 \pm 0,14$ & $410 \pm 10,8 \times 10^{6}$ \\
5 Hayvan & $1,7 \pm 0,25$ & $520 \pm 43,2 \times 10^{6}$ \\
6. Hayvan & $1,4 \pm 0,14$ & $465 \pm 36,29 \times 10^{6}$ \\
7. Hayvan & $2,2 \pm 0,21$ & $505 \pm 20,41 \times 10^{6}$ \\
8. Hayvan & $1,8 \pm 0,14$ & $595 \pm 42,62 \times 10^{6}$ \\
9. Hayvan & $1,9 \pm 0,16$ & $560 \pm 35,59 \times 10^{6}$ \\
10. Hayvan & $1,5 \pm 0,33$ & $555 \pm 30,82 \times 10^{6}$ \\
\hline
\end{tabular}

Tablo 2. Aksaray Malaklı Köpeklerinde Metiyonin ve Trehalozun çözüm sonu spermatolojik parametrelere etkisi

Table 2. Evaluation of additives on dog sperm parameters (Motility, Live-Dead, HOS test) after thawing

\begin{tabular}{|c|c|c|c|}
\hline Gruplar & Motilite (\%) & Canlı Spermatozoa (\%) & HOS Test (\%) \\
\hline Kontrol & $41,5 \pm 3,1^{b}$ & $57,8 \pm 2,3$ & $33,2 \pm 2,9^{b}$ \\
\hline Trehaloz (10 $\mathrm{mM})$ & $50,0 \pm 3,9 \mathrm{ab}$ & $60,6 \pm 3,7$ & $38,4 \pm 3,6^{\mathrm{ab}}$ \\
\hline Metiyonin (2mM) & $52,5 \pm 2,7 \mathrm{a}$ & $63,6 \pm 2,2$ & $43,1 \pm 2,9^{a}$ \\
\hline $\mathrm{p}$ & $0,05^{*}$ & - & $0,05^{*}$ \\
\hline
\end{tabular}

a-b: Aynı sütunda farklı harf taşıyan gruplar istatistiksel olarak farklıdır $(\mathrm{p}<0,05)$.

a-b: Different superscripts within the same column demonstrate significant differences $(\mathrm{p}<0.05)$.

\section{TARTIŞMA}

Köpek spermasının dondurulması, hem üreme amaçlı hem ticari amaçlı köpekler için önem kazanmaktadır. Köpekler de dahil olmak üzere, memeli spermatozoalarının dondurulmasi, sperma fertilitesi üzerinde bazı olumsuz etkiler yaratması bu tekniğin daha az kullanılmasına neden olmaktadır (Singh veark. 2012, Bucci ve ark. 2019).Kriyoprezervasyon,tüm memeli türlerinin sperm membranlarını etkilemesi sebebiile kapsaml kimyasal ve fiziksel hasara neden olmaktadir (Watson 2000).Hasarın nedeni, lipit fazdan geçiş esnasında ROS tarafindan indüklenen membranın lipid peroksidasyonunda (LPO), ozmotik stres ve sıcaklık değissimlerinden dolayı hücre zarları üzerindeki mekanik strese bağlı olarak değişebilir (Ortega Ferrusolave ark. 2009, Câmara ve ark. 2011).Bu araştırmada, sulandırıcıya eklenen metiyonin ve trehalozun köpek spermasinda çözüm sonu motilite, ölü-canlı ve HOS test sonuçları üzerine etkileri değerlendirilmiştir.
Walczak Jedrzejowska ve ark. (2012) in vitro ve in vivo çalışmalarda, birçok antioksidan faktörün sperm, gebelik oranı ve canlı doğum oranları üzerine yararlı etkileri olduğunu belirtmişlerdir. Serbest radikallerin zararlı etkilerinden korunmak için hücreler bunları nötralize eden antioksidanlar meydana getirmektedir. Serbest radikallerin oluşum hizı ve bunların antioksidanlar tarafindan nötralize edilme hizı arasinda bir denge olması gereklidir. (Tekcan 2009). Sperma sulandirıcısına antioksidan ilavesi, çözüm sonu sperm parametrelerinin iyileștirilmesi için en umut verici tekniklerden birisi olduğu birçok araştırmacı tarafindan belirtilmektedir. (Peña ve ark.2006, Ogatave ark. 2015). Demirtaş ve Üntan (2011) antioksidanların spermatozoayı serbest oksijen radikalleri (SOR) üreten anormal spermatozoalardan koruduğunu, lökositlerin oluşturduğu SOR'u temizlediğini, DNA kırılmalarını ve erken sperm olgunlaşmasını engellediğini, soğuk şokuna karşı spermatozoayı koruduğunu ve destekleyerek üreme tekniklerinin başarısını yükselttiğini belirtmişlerdir. $\mathrm{Bu}$ çalışmada, köpek sperma sulandırıcısına eklenen Metiyonin 2 mM' in çözüm sonu motilite ve plasma 
membran bütünlügüne olumlu etki gösterdiği belirlendi. Buna karșıllk, çözüm sonu canlı spermatozoa oranına belirli ölçüde fayda sağlamakla birlikte istatistiksel fark oluşturmamıştır. Çalışmada ön değerlendirme amaciyla alınan spermaların bireysel yoğunluk değerleri İnanç ve ark. (2018) Aksaray malaklısı çalışmasından yüksek elde edildi. Elde edilen bu sonucun diğer çalışmada yaş gruplarına göre oluşturulmuş olan gruplardan dolayı oluşacağ1 kanısına varıldı. Çalışmamızdaki kontrol grubunda elde edilen çözüm sonu motilite ve canll1ık değerleri İnanç ve ark. (2018) çözüm sonu sonuçları ile benzerlik göstermektedir. Bunun yanı sıra elde edilen bu sonuçlar, Anadolu çoban köpeklerinin spermasının dondurulması soncunda çözüm sonu motilite ve canlı spermatozoa oranları benzer bulunmuştur (Güngör ve Bucak 2016).

Trehaloz, sperma hücrelerini, ROS'un olumsuz etkilerinden nonenzimatik bir temizleyici gibi etki göstererek korur (Badr ve ark. 2010) ve uygun seviyelerde dondurulmuş sperm hücrelerinin çözüm sonu motilitesini ve membran bütünlügünü korumak için gerekli olan enerjiyi sağlar(Flores ve ark. 2010). El-Badry ve ark.(2017) nin yapmış olduğu çalışmadan farklı olarak bu çalışmada, sperma sulandırıcısına 10 $\mathrm{mM}$ trehaloz eklenmesi, membran bütünlüğ̈ üzerine kontrol grubuna kiyasla olumlu etki gösterirken istatistiksel fark oluşturmamıştır. Motilite ve canlı sperma oranlarında faydalı olmasına rağmen Trehalozun spermatolojik parametreler üzerine etkisini inceleyen bazı araştırmacılar, koç (Sharawy ve ark. 2015), bufalo (Iqbal ve ark.2016), horoz (Mosca ve ark. 2016) ve boğa (El-Sheshtawy ve ark. 2015) spermasında çözüm sonu değerlerinde iyileşme olduğunu belirtmişlerdir. Benzer sonuçların sulandirıciya katkı maddesi eklenerek dondurulan Aksaray Malaklı spermasında da İnanç ve ark. (2018) tarafindan elde edildiği belirtilmiştir.

Metiyonin, esansiyel bir amino asittir. Glutatyon öncüsü olması ile ROS'u azaltan ve böylece hücreleri oksidatif strese karşı koruyan bir tripeptid olduğu için antioksidan özelliklere sahiptir. Ayrıca, çekirdek ve hücre bölünmesi olaylarında yer alan poliaminlerin (spermin ve spermidin) ve DNA ve diğer moleküllerin metilasyon reaksiyonları içinmetil grubu sentezinde metiyonin gerekir (Bouyeh 2012).Metiyonin, metiyonin sülfoksit oluşturmak için oksidanlarla kolayca reaksiyona girerek antioksidan savunmasında önemli bir rol oynamaktadır(Livine ve ark. 1999).Yapılan çalıșmalarda sulandırıcıya $2 \mathrm{mM}$ Metiyonin ilavesi, çözüm sonu sperma motilitesini kontrol grubuna kıyasla arttırdığ belirlenmiştir(Çoyan ve ark. 2010,Bucak ve ark.2012). Ayrica, Tuncer ve ark. (2010) tarafindan metiyonin üç farklı dozunun (2,5,5 ve $10 \mathrm{mM}$ akrozom bütünlüğünü soğuk şokundan başarıyla korunduğu belirtilmiştir.

\section{SONUÇ}

Yapılan bu çalışma ile metiyonin $2 \mathrm{mM}$ ve trehalozun $10 \mathrm{mM}$ dozlarının çözüm sonu spermatolojik parametreleri koruduğu metiyoninin kontrol grubu ile istatistiksel fark oluşturacak şekilde olumlu etki sağladığ1 sonucuna varılmıştır. Köpek sperması kriyoprezervasyonunda metiyonin ve trehaloz içeren sulandirıciların kullanilmasi ve yapilacak yeni çalışmalar ile farklı dozların denenmesi önerilebilir.

\section{TEŞEKKÜR}

Bu çalısma Tübitak 2209-A Üniversite Öğrencileri Arastirma Projeleri tarafindan (Proje no: 1919B011602713) desteklenmistir ve 9. Ulusal Reprodüksiyon ve Suni Tobumlama Bilim Kongresi'nde sunulmustur.

Sunulan çallsma için Mehmet Akif Ersoy Üniversitesi Hayvan Deneyleri Yerel Etik Kurulu'ndan gerekli izin (2016/217) alndi.

\section{KAYNAKLAR}

Abdelhakeam AA, Graham EF, Vazquez IA, Chaloner KM. Studies on the absence of glycerol in unfrozen and frozen ram semen: Development of an extender for freezing: Effects of osmotic pressure, egg yolk levels, type of sugars, and the method of dilution. Cryobiology. 1991; 28: 43-49.

Agarwal A, Cocuzza M, Abdelrazik H, Sharma RK. "Oxidative stress measurement in patients with male or female factor infertility". Handbook of Chemiluminescent Methods in Oxidative Stress Assessment. 2008; 195-218.

Agarwal A, Durairajanayagam D, Halabi J, Peng J, Vazquez-Levin M. Proteomics, oxidative stress and male İnfertility. Reproductive BioMedicine Online. 2014; 29: 32-58.

Akalın PP, Başpınar N, Çoyan K, Bucak MN, Ataman MB, Ömür AD, Bilgili A, Güngör Ş, Sarıözkan S, Öztürk C, Bodu M, Acibaeva B. Metiyonin ve Trehaloz İçeren Sulandırıcıların Koç Spermasının Dondurma-Çözdürme Sonrası Sperm Akrozom Bütünlüğü ve Biyokimyasal Parametreleri Üzerine Etkileri. Bahri Dağdaş Hayvancıllk Araştırma Dergisi. 2015; 3(1): 7-15.

Álamo D, Batista M, González F, Rodríguez N, Cruz G, Cabrera F, Gracia A. Cryopreservation of semen in the dog: use of ultra-freezers of $-152^{\circ} \mathrm{C}$ as a viable alternative to liquid nitrogen. Theriogenology. 2005; 63(1): 72-82.

Atasoy F, Erdoğan M, Özarslan B, Yüceer B, Kocakaya A, Akçapınar H. Malaklı Karabaş köpeklerde bazı morfolojik ve genetik özellikler. Ankara Üniv Vet Fak Derg. 2014; 61: 125-132.

Badr MR, Abd El- Malak MG, Hassan HM. Effect of trehalose on cryopreservation, oxidative stress and DNA integrity of buffalo spermatozoa.J Reprod Infertil. 2010; 1: $50-57$.

Bencharif D, Amirat-Briand L, Garand A, Anton M, Schmitt E, Desherces S, Delhomme G, Langlois M, Barriere $\mathbf{P}$, Destrumelle S, Vera-Munoz $\mathbf{O}$, Tainturier $\mathbf{D}$. The advantages of using a combination of LDL and glutamine in comparison with TRIS egg yolk and Equex STAMP extenders in the cryopreservation of canine sperm.Research in Vet Science. 2012; 93: 440-447. 
Bilodeau JF, Blanchette S, Gagnon IC, Sirard MA. Thiols prevent H2O2-mediated loss of sperm motility in cryopreserved bull semen. Theriogenology.2001; 56: 275286.

Bouyeh M. Effect of excess lysine and methionine on immune system and performance of broilers. Ann Biol Res. 2012;3(7): 3218-3224.

Bucak MN, ÇoyanK, Öztürk C, Güngör Ş, Ömür AD. Methionine supplementation improves ram sperm parameters during liquid storage at 5 C.Cryobiology.2012; 65(3): 335-337.

Bucci D, Cunto M, Gadani B, Spinaci M, Zambelli D, Galeati G. Epigallocatechin-3-gallate added after thawing to frozen dog semen: Effect on sperm parameters and ability to bind to oocytes' zona pellucida.Reproductive biology.2019; 19(1): 83-88.

Câmara DR, Silva SV, Almeida FC, Nunes JF, Guerra MM. Effects of antioxidants and duration of pre-freezing equilibration on frozenthawed ram semen.Theriogenology.2011; 76: 342-350.

Çoyan K, Başpınar N, Bucak MN, Akalın PP, Ataman MB, Ömür AD, Güngör Ş, Küçükgünay S, Özkalp B, Sarıözkan S. Influence of methionine and dithioerythritol on sperm motility, lipid peroxidation and antioxidant capacities during liquid storage of ram semen. Research in Veterinary Science.2010; 89(3): 426-431.

Demirtaş A, Üntan İ. Seminal sıvı ve spermde oksidatif stres ve antioksidanlar.Türk Ürol Sem.2011; 2: 24-30.

El-Alamy MA, Foote RH. Freezability of spermatozoa from Finn and Dorset rams in multiple semen extenders.Anim Reprod Sci.2001; 65: 245-254.

El-Badry DA, El-Maaty AMA, Gamal A. The effect of trehalose supplementation of INRA-82 extender on quality and fertility of cooled and frozen-thawed stallion spermatozoa.Journal of equine veterinary science.2017; 48: 86-92.

El-Sheshtawy RI, Sisy GA, El-Nattat WS. Effects of different concentrations of sucrose or trehalose on the postthawing quality of cattle bull semen.Asian Pacific Journal of Reproduction.2015; 4(1): 26-31.

England GC. Cryopreservation of dog semen: a review. Journal of reproduction and fertility. 1992; 47: 243-255.

Flores JA, Fernández A, Huamán U, Ruiz G, Santiani A. Refrigeration of canine semen using glucose, fructose, trehalose or sucrose to extend sperm survival.Rev Inv Vet Perú. 2010; 21: 26-34.

Garcia MA, Graham EF. Development of a buffer system for dialysis of bovine spermatozoa before freezing. II. Effect of sugars and sugar alcohols on posthaw motility.Theriogenology.1989; 31: 1029-1237.

Gungor S, Bucak MN.Basal medium eagle solution may improve the post-thaw parameters of Kangal dog semen.Eurasian J Vet Sci. 2016; 32: 193-199.

Gungor S, Ata A, Inanc ME. Effects of trehalose and catalase on the viability and kinetic parameters of cryopreserved ram sperm. Acta Scientiae Veterinariae. 2018; 46: 1.

Guthrie HD, Welch GR. Effects of reactive oxygen species on sperm function. Theriogenology.2012; 78: 1700-1708.

Inanc ME, Tekin K, Olgac KT, Yilmaz B, Cil B, Tasdemir U, Tuncer BP, Buyukleblebici S, Durmaz E, Uysal O. Effect of cholesterol loaded cyclodextrin on semen cryopreservation of Aksaray Malakli shepherd dogs of different ages. Animal Reproduction Science.2018; 193: $191-200$
Iqbal S, Andrabi SMH, Riaz A, Durrani AZ, Ahmad N. Trehalose improves semen antioxidant enzymes activity, post-thaw quality, and fertility in Nili Ravi buffaloes (Bubalus bubalis). Theriogenology.2016; 85(5): 954-959.

Kim JG, Parthasarathy S. Oxidation and the spermatozoa. In Seminars in reproductive endocrinology.1998; 16: 235339.

Kulaksız R, Daşkın A. Farklı antioksidanlarla dondurulan Saanen teke spermasinin in vitro ve in vivo değerlendirilmesi. Ankara Üniv Vet Fak Derg.2009; 56: 201-205.

Kulaksız R. Farklı antioksidanlar eklenmiş sulandırıcılarla dondurulmuş Saanen teke spermasının in vitro değerlendirilmesi. Doktora tezi, Ankara Üniversitesi Sağllk Bilimleri Enstitüsü, Ankara, 2009.

Liu Z, Foote RH, Brockett CC. Survival of bull sperm frozen at different rates in media varying in osmolarity. Cryobiology.1998; 37(3): 219-230.

Livine RL, Berlett BS, Moskovitz J, Mosoni L, Stadtman ER. Methionine residues may protect proteins from critical oxidative damage. Mech Ageing Dev.1999; 107: 323-332.

Malo C, Gil L, Gonzalez N, Cano R, Blas I, Espinosa E. Comparing sugar type supplementation for cryopreservation of boar semen in egg yolk based extender. Cryobiology.2010; 61(1): 17-21.

Martins-Besa A, Rocha A, Maenco-Aguirre A. Incorporation of taurine and hypotaurine did not improve the efficiency of the Uppsala Equex II extender for dog semen freezing. Theriogenology.2007; 68: 1088-1096.

Michael AJ, Alexopoulos C, Pontiki EA, Hadjipavlou-Litina DJ, Saratis P, Ververidis HN, Boscos CM. Effect of antioxidant supplementation in semen extenders on semen quality and reactive oxygen species of chilled canine spermatozoa. Animal Rep Science.2009; 112: 119135.

Molinia FC, Evans G, Casares PI, Maxwell WMC. Effect of monosaccharides and disaccharides in tris based diluents on motility, acrosome integrity and fertility of pellet frozen ram spermatozoa. Animal Reproduction Science.1994; 36: 113-122.

Mosca F, Madeddu M, Sayed AA, Zaniboni L, Iaffaldano N, Cerolini S. Data on the positive synergic action of dimethylacetamide and trehalose on quality of cryopreserved chicken sperm. Data in brief. 2016; 9: 1118-1121.

Neagu VR, García BM, Sandoval CS, Rodríguez AM, Ferrusola CO, Fernández LG, Tapia JA, Peña, FJ. Freezing $\operatorname{dog}$ semen in presence of the antioxidant butylated hydroxytoluene improves postthaw sperm membrane integrity. Theriogenology.2010; 73(5); 645650 .

Ogata K, Sasaki A, Kato Y, Takeda A, Wakabayashi M, Sarentonglaga B. Glutathione supplementation to semen extender improves the quality of frozenthawed canine spermatozoa for transcervical insemination. J Reprod Dev.2015; 61; 116-122.

Ortega Ferrusola C, González Fernández L, Morrell JM, Salazar Sandoval C, Macías García B, RodríguezMartinez H. Lipid peroxidation, assessed with BODIPY-C11, increases after cryopreservation of stallion spermatozoa, is stallion dependent and is related to apoptotic-like changes. Reproduction.2009; 138; 55-63.

Patra RC, Swarup D, Dwivedi SK. Antioxidant effects of alpha-tocopherol, ascorbic acid and L-methionine on lead 
induced oxidative stress to the liver, kidney and brain in rats. Toxicology.2001; 162; 81-88.

Peña FJ, Núñez-Martínez I, Morán JM. Semen technologies in dog breeding: an update.Reproduction in Domestic Animals.2006; 41(s2); 21-29.

Reddy NSS, Mohanarao GJ, Atreja SK. Effects of adding taurine and trehalose to a tris-based egg yolk extender on buffalo (Bubalus bubalis) sperm quality following cryopreservation.Animal Reproduction Science.2010; 119(3): 183-190.

Reed DJ. Glutathione: toxicological implications. Annu Rev Pharmacol Toxicol.1990; 30: 603-631.

Sabuncuoğlu S, Özgüneş H. Kemoterapi, serbest radikaller ve oksidatif stres.Hacettepe Üniversitesi Eczacllık Fakültesi Dergisi.2011; 31(2): 137-50.

Sharawy SM, Saleh NH, Attalah SA, Absy GM, Doaa HK. Studies on the effect of added ascorbic acid and trehalose to tris buffered egg yolk extender on chilled ram semen. MENA Sci J.2015; 1: 1-4.

Singh VK, Atreja SK, Kumar R, Chhillar S,Singh AK. Assessment of intracellular $\mathrm{Ca}^{2+}$, cAMP and 1,2diacylglycerol in cryopreserved buffalo (Bubalus bubalis) spermatozoa on supplementation of taurine and trehalose in the extender. Reprod Dom Anim.2012; 47: 584-590.

Storey BT, Noiles EE, Thompson KA. Comparison of glycerol other polyols, trehalose, and raffinose to provide a defined cryoprotectant medium for mouse sperm cryopreservation. Cryobiology.1998; 37: 46-58.

Tekcan M. Oksidatif stres-antioksidan sistemler ve testis. Androloji Bülteni.2009; 37: 131-136.

Tekin N. Spermanın muayenesi ve değerlendirilmesi, Evcil Hayvanlarda Reprodüksiyon, Sun'i Tohumlama, Doğum ve İnfertilite,Ed. E. Alaçam, Dizgievi, Konya. 1994; pp 69-70.

Tosun H, Uysal O. Köpek spermasının dondurulmasında farklı sulandırıcıların ve bireylerin etkisi.Ankara Üniv Vet Fak Derg.2007; 54(1): 23.

Tuncer PB, Bucak MN, Sarıözkan S, Sakin F, Yeni D, Çiğerci İH, Büyükleblebici O. The effect of raffinose and methionine on frozen/thawed Angora buck (Capra hircus ancryrensis) semen quality, lipid peroxidation and antioxidant enzyme activities.Cryobiology.2010; 61(1), 8993.

Uysal O, Bucak MN, Yavaş İ, Varışlı Ö, Gurcan IS. Evaluation of ram Sperm frozen with various taurine concentrations. Indian Vet J.2005; 82: 1059-1061.

Walczak-Jedrzejowska R, Wolski JK, Slowikowska-Hilczer J. The role of oxidative stress and antioxidants in male fertility.Central Eur J Urology.2012; 66: 60-67.

Watson PF. The Causes of Reduced Fertility with Cryopreserved Semen.Anim Reprod Sci.2000; 60: 481-492.

Watson PF. Use of Giemsa stain to detect changes in the acrosome of frozen ram spermatozoa.Vet Rec.1975; 97(1): 12-15.

Woelders H, Matthijs A, Engel B. Effects of trehalose and sucrose, osmolality of the freezing medium, and cooling rate on viability and intactness of bull sperm after freezing and thawing.Cryobiology.1997; 35: 93-105. 